\title{
Annoyance due to air pollution in Europe
}

\author{
Bénédicte Jacquemin, ${ }^{1 *}$ Jordi Sunyer, ${ }^{1,2}$ Bertil Forsberg, ${ }^{3}$ Thomas Götschi, ${ }^{4}$ Lucy Bayer-Oglesby, \\ Ursula Ackermann-Liebrich, ${ }^{5}$ Roberto de Marco, ${ }^{6}$ Joachim Heinrich, ${ }^{7}$ Deborah Jarvis, ${ }^{8}$ Kjell Torén ${ }^{9}$ \\ and Nino Künzli ${ }^{1,4}$
}

\begin{abstract}
Accepted 15 February 2007
Background Annoyance due to air pollution is a subjective score of air quality, which has been incorporated into the National Environmental monitoring of some countries. The objectives of this study are to describe the variations in annoyance due to air pollution in Europe and its individual and environmental determinants.
\end{abstract}

Methods This study took place in the context of the European Community Respiratory Health Survey II (ECRHS II) that was conducted during 1999-2001. It included 25 centres in 12 countries and 7867 randomly selected adults from the general population. Annoyance due to air pollution was self-reported on an 11-point scale. Annual mean mass concentration of fine particles $\left(\mathrm{PM}_{2.5}\right)$ and its sulphur (S) content were measured in 21 centres as a surrogate of urban air pollution.

Results Forty-three per cent of participants reported moderate annoyance ( $1-5$ on the scale) and $14 \%$ high annoyance $(\geqslant 6)$ with large differences across centres ( $2-40 \%$ of high annoyance). Participants in the Northern European countries reported less annoyance. Female gender, nocturnal dyspnoea, phlegm and rhinitis, self-reported car and heavy vehicle traffic in front of the home, high education, non-smoking and exposure to environmental tobacco smoke were associated with higher annoyance levels. At the centre level, adjusted means of annoyance scores were moderately associated with sulphur urban levels (slope $1.43 \mu \mathrm{g} \mathrm{m}^{-3}$, standard error $0.40, r=0.61$ ).

Conclusions Annoyance due to air pollution is frequent in Europe. Individuals' annoyance may be a useful measure of perceived ambient quality and could be considered a complementary tool for health surveillance.

Keywords Annoyance, air pollution, respiratory symptoms

\footnotetext{
${ }^{1}$ Municipal Institute of Medical Research, Barcelona, Spain.

${ }^{2}$ Universitat Pompeu Fabra, Barcelona, Spain.

${ }^{3}$ Umeå University, Umeå, Sweden.

${ }^{4}$ University of Southern California, Los Angeles, USA.

${ }^{5}$ Institute of Social and Preventive Medicine, University of Basel, Basel, Switzerland.

${ }^{6}$ Verona University, Verona, Italy.

${ }^{7}$ GSF Institute of Epidemiology, Munich, Germany.

${ }^{8}$ King's College London, London, UK.

9 Sahlgrenska University Hospital, Göteborg, Sweden.

* Corresponding author: Bénédicte Jacquemin, Centre for Research in Environmental Epidemiology (CREAL), Municipal Institute of Medical Research, IMIM, Barcelona Biomedical Research Park (office 183.01 A), Dr Aiguader 88, 08003-Barcelona, Spain.

E-mail: bjacquemin@imim.es
}

\section{Introduction}

Air pollution is a risk factor for respiratory and cardiovascular diseases. $^{1,2}$ It is now accepted that air pollution is an important issue in public health given its impact on long-term mortality. ${ }^{3}$ However, the assessment of exposure to air pollution is complicated. Most of the epidemiological studies that assess health effects of air pollution use central site measurements, in some cases weighted by the distance between participants' homes and a main road, ${ }^{4}$ or individual patterns of daily activity. ${ }^{5}$ Another type of measure incorporating broader scopes and domains (such as quality of life or community values) is annoyance due to air pollution. ${ }^{6}$ It is a subjective score, often used for measuring noise or odours, ${ }^{7}$ but rarely used for air pollution exposure. In Sweden, this measure has been incorporated in the National Environmental monitoring program and urban citizens' annoyance correlated with urban air 
pollution even if pollutant levels were well below thresholds. ${ }^{8}$ Oglesby et al. have shown across eight Swiss towns and neighbourhoods within these areas that the aggregate group mean annoyance correlated with the air quality in the city or neighbourhood. In contrast, individual reporting of annoyance was only weakly associated with outdoor levels of air pollution. ${ }^{9}$ Rotko et al. have shown that at the population level, the mean annoyance was correlated with mean $\mathrm{PM}_{2.5}$ and $\mathrm{NO}_{2}$ concentrations across six European cities, but individual annoyance was not associated with individual $\mathrm{PM}_{2.5}$ or $\mathrm{NO}_{2}$ concentrations. ${ }^{10}$

Besides air quality, individual characteristics affect the reporting of annoyance, leading to substantial subjectivity of annoyance scores. In previous studies, several variables such as gender, age, education or respiratory symptoms have been associated with annoyance due to air pollution but not consistently. ${ }^{8,10-12}$ The rate of respondents highly annoyed by air pollution at home also varied across different European cities. ${ }^{8-10}$ It is not possible to generalize these results across cultures and countries as the previous studies were restricted to few areas.

The objectives of this study are to describe the personal and socio-demographic determinants of annoyance due to air pollution in a large international multicultural European study and to assess its association with central measurements of air pollution.

\section{Materials and methods}

\section{Study population}

The European Community Respiratory Health Survey (ECRHS) was conducted in 28 urban centres of 11 Western European countries. ${ }^{13}$ It was first conducted in 1991-93 and repeated in 1999-2001. The objective was to estimate the variation in the prevalence, exposure, risk factors and treatment of respiratory diseases, especially asthma, in middle-aged adults living in Europe. Centres were chosen based on pre-existing administration boundaries, their size and the availability of sampling frames. Participants were randomly selected from the populations aged 20-44 in 1991-93. The details of this project are described elsewhere. ${ }^{13,14}$

This analysis is based on the second survey and includes all centres that used the annoyance question and data on 7867 participants from 25 centres in 12 countries (Figure 1). Sample size varied by centre from 123 in Turin (Italy) to 596 in Bergen (Norway). The response rate for this stage was $65.3 \%$, ranging from $30.3 \%$ in Bordeaux (France) to $83.1 \%$ in Uppsala (Sweden).

\section{Description of variables}

Annoyance due to air pollution was self-reported on an 11 point scale (0: no disturbance at all, 10: intolerable disturbance) through the following question: 'How much are you annoyed by outdoor air pollution (from traffic, industry, etc.) if you keep the windows open?' The overall response rate for this question was $97.9 \%$ among study participants. All determinants of annoyance have been collected within the same questionnaire. The variables for the analysis were chosen based on previous studies. ${ }^{8-11}$ Socio-demographic factors were age, gender, education (based on age at end of study and categorized in tertiles) and socio-economic class (based on occupation). The respiratory variables included in the analysis were wheezing, breathless while wheezing, wheezing without a cold, shortness of breath at rest (dyspnoea), shortness of breath while sleeping (night dyspnoea), cough in winter, phlegm during day or night in winter, phlegm during day or night in winter for more than three months, asthma attack in the last 12 months (current asthma), asthma treatment, rhinitis without a cold in the last 12 months (current rhinitis) and in addition having ever had asthma or rhinitis and season of the rhinitis. The lifestyle factors were frequency of physical exercise, smoking and exposure to environmental tobacco smoke (ETS), defined as regular exposure to tobacco smoke at home and/or at work. Finally, the questionnaire asked about general as well as heavy vehicle traffic intensity in front of the home. This information was collected from a four-option question, where the options were no traffic, infrequent, frequent and constant traffic.

\section{Air pollution measurements}

Annual means of fine particulate matter $\left(\mathrm{PM}_{2.5}\right)$ (fine particles with a median size of $2.5 \mu \mathrm{m}$ aerodynamic diameter) and its elemental content were available for 21 centres from a 12-month measurement campaign. Sulphur represents a background portion of $\mathrm{PM}_{2.5}$, mainly consisting of sulphate particles $\left(\mathrm{SO}_{4}^{2-}\right)$, which are oxidation products formed from sulphur dioxide $\left(\mathrm{SO}_{2}\right)$ emissions during long-range transportation in the atmosphere. Concentrations measured in one location characterized the level of this long-range pollution for the city at large, and correlations between fixed-site monitors, home outdoor and even personal concentrations are very high for S. Thus, it reflects the 'regional' air quality whereas other pollutants characterize more local emissions. We use the annual mean mass concentration of sulphur measured on fine particles with a median size of $2.5 \mu \mathrm{m}$ aerodynamic diameter $\left(\mathrm{PM}_{2.5}\right)$. These measurements are available for 21 centres from a 12-month measurement campaign described elsewhere. ${ }^{15-17}$ In brief, between June 2000 and December 2001, at a central monitoring site, 7 days were sampled over a 2 -week period during each month, using identical equipment and procedures in each centre. $\mathrm{S}$ content on $\mathrm{PM}_{2.5}$ filters was analysed using energy dispersive X-ray fluorescence spectrometry (ED-XRF). Both $\mathrm{PM}_{2.5}$ and $\mathrm{S}$ concentrations are reported in $\mu \mathrm{g} \mathrm{m}^{-3}$.

\section{Statistical analysis}

The statistical analysis was performed in two steps. In a first step, personal determinants of annoyance were identified by univariate negative binomial regression, entering centre as a fixed effect if the $P$ value from the test of heterogeneity was $<0.10$, and entering centre as a random effect if $P$ was $>0.10$. The results are expressed as ratios of mean annoyance scores. Effect estimates were derived for each centre and heterogeneity across centres was examined using standard methods. ${ }^{18}$ 


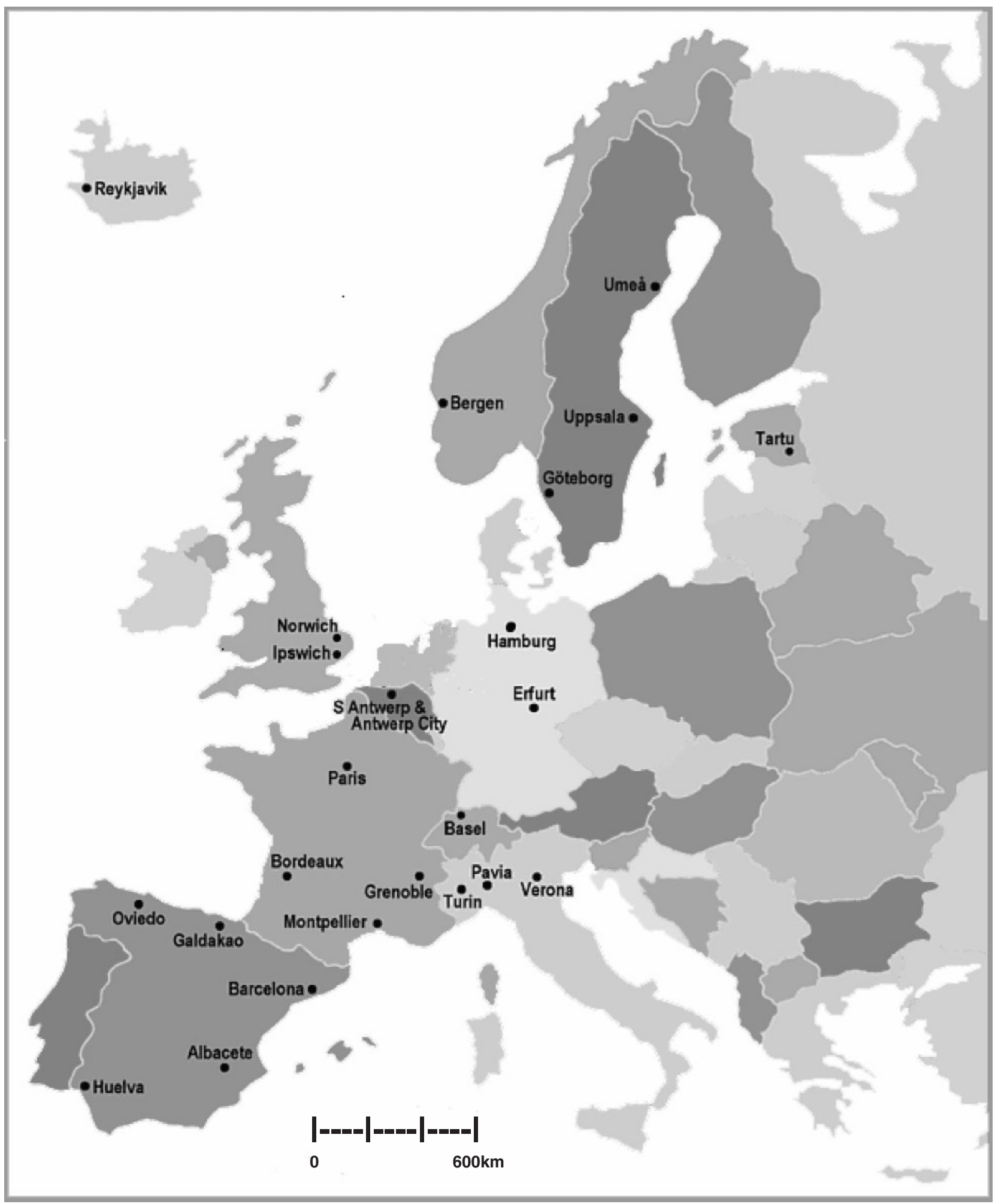

Figure 1 Map of Europe with the centres participating in the European Community Respiratory Health Survey II (ECRHSII).

Negative binomial regression was also used for the multivariate model. The model was created in a forward procedure including variables with $P<0.20$ in the crude analysis and then retaining the ones with $P<0.10$. A backwards procedure resulted in the same selection of covariates. Socio-economic status and smoking were forced in the model, due to their association with annoyance in the bivariate analysis and to the social implications. The multivariate model was adjusted for centre. 
In a second step, the data was analysed on the centre level, regressing the centre-wide average annoyance against the city mean regional air pollutant: $\mathrm{PM}_{2.5}$ or $\mathrm{S}$. The mean annoyance was calculated crudely initially and then adjusted for the variables identified previously as associated with annoyance in the multivariate analysis. The mean annoyance per centre was calculated using the mean of the predicted values from the negative binomial regression model in each centre. For the crude mean annoyance, the negative binomial regression was univariate and for the adjusted mean, the negative binomial regression was multivariate, including the co-variables of interest. The association of ambient $\mathrm{PM}_{2.5}$ and $\mathrm{S}$ with both the crude and adjusted average annoyance at the centre level was measured with a linear regression model, weighted by centre's sample size. Thus, the crude model reflects a purely ecological association. The adjusted models were controlled for all potential individual-level confounding variables, except the reported traffic density. The last model was also adjusted for the reported traffic density at home.

The analysis was done using STATA 8 (Stata Corporation, College Station, TX, USA). The criterion for statistical significance was set at a $P$ value $<0.05$.

\section{Results}

Overall, 3406 (43\%) participants reported no annoyance at all (0 on the scale), $3352(43 \%)$ reported low to moderate annoyance ( 1 to 5 ) and 1109 (14\%) reported high annoyance $(\geqslant 6)$. Only $489(6 \%)$ individuals were very highly annoyed $(8-10) .{ }^{9}$ The overall mean was 2.21 and the median 1.0. Table 1 shows the centres ordered by the mean level of annoyance, which ranged from 0.69 in Bergen (Norway) to 4.38 in Huelva (Spain). The percentage of participants reporting $\geqslant 6$ on the annoyance scale varied from $2 \%$ in Reykjavik (Iceland) to $41 \%$ in Huelva. Reykjavik and Bergen scores were significantly lower than those in all other centres. In general, participants in the Northern European countries reported less annoyance. The annual means of $\mathrm{PM}_{2.5}$ varied from $3.74 \mu \mathrm{g} \mathrm{m}^{-3}$ in Reykjavik to $44.86 \mu \mathrm{g} \mathrm{m}^{-3}$ in Turin. The annual means of $\mathrm{S}$ varied from $0.16 \mu \mathrm{g} \mathrm{m}^{-3}$ in Reykjavik to $2.02 \mu \mathrm{g} \mathrm{m}^{-3}$ in Verona (Table 1).

For the individual variables, female gender, socio-economic class, all the respiratory outcomes, passive smoking and selfreported car and heavy vehicle traffic were associated with annoyance (Table 2). Age, education, exercise, smoking and season of the interview were not associated with annoyance. There was little evidence for heterogeneity across centres,

Table 1 Median, interquartile range and mean annoyance scores (from 0 to 10 ), percentage of subjects reporting high annoyance ( $\geqslant 6$ ) and $\mathrm{PM}, 5$ and $\mathrm{S}$ levels in participating study centres

\begin{tabular}{|c|c|c|c|c|c|c|c|c|}
\hline Centre & $n$ & p25\% & p50\% & p75\% & Mean & $\begin{array}{r}\text { Percentage reporting } \\
\text { high annoyance }\end{array}$ & $\begin{array}{l}\text { Annual mean of } \\
\mathbf{P M}_{2.5} \text { in } \mu \mathrm{g} \mathrm{m}^{-3}\end{array}$ & $\begin{array}{l}\text { Annual mean } \\
\text { of } S \text { in } \mu \mathrm{g} \mathrm{m}^{-3} \\
\end{array}$ \\
\hline Bergen & 558 & 0 & 0 & 0 & 0.69 & 3 & - & - \\
\hline Reykjavik (RE) & 460 & 0 & 0 & 1 & 0.71 & 2 & 3.74 & 0.16 \\
\hline Göteborg (GO) & 489 & 0 & 0 & 1 & 1 & 4 & 12.62 & 0.90 \\
\hline Uppsala (UP) & 516 & 0 & 0 & 1 & 1.01 & 5 & 10.40 & 0.75 \\
\hline Umeå (UM) & 416 & 0 & 0 & 2 & 1.5 & 7 & 5.61 & 0.41 \\
\hline Bordeaux & 165 & 0 & 0 & 3 & 1.82 & 10 & - & - \\
\hline Norwich (NO) & 256 & 0 & 1 & 3 & 1.83 & 10 & 16.20 & 0.98 \\
\hline Pavia (PA) & 192 & 0 & 0 & 3 & 1.84 & 13 & 35.27 & 1.78 \\
\hline Hamburg & 303 & 0 & 1 & 3 & 1.92 & 10 & - & - \\
\hline South Antwerp (SA) & 294 & 0 & 2 & 3 & 2.1 & 10 & 20.78 & 1.45 \\
\hline Tartu (TA) & 259 & 1 & 2 & 3 & 2.5 & 11 & 14.75 & 0.89 \\
\hline Oviedo (OV) & 241 & 0 & 2 & 5 & 2.59 & 17 & 15.88 & 1.18 \\
\hline Erfurt (ER) & 285 & 0 & 2 & 4 & 2.6 & 14 & 16.25 & 1.14 \\
\hline Galdakao (GA) & 359 & 0 & 2 & 5 & 2.61 & 16 & 16.25 & 1.58 \\
\hline Grenoble (GN) & 384 & 0 & 2 & 5 & 2.67 & 16 & 19.01 & 0.89 \\
\hline Montpellier & 202 & 1 & 2 & 5 & 2.84 & 16 & - & - \\
\hline Verona (VE) & 205 & 0 & 2 & 5 & 2.84 & 22 & 41.52 & 2.02 \\
\hline Ipswich (IP) & 281 & 0 & 2 & 5 & 2.9 & 22 & 16.45 & 1.00 \\
\hline Albacete (AL) & 294 & 0 & 3 & 5 & 3.1 & 19 & 13.13 & 1.01 \\
\hline Basel (BS) & 446 & 0 & 2 & 5 & 3.11 & 24 & 17.42 & 1.04 \\
\hline Turin (TU) & 123 & 0 & 3 & 6 & 3.3 & 25 & 44.86 & 1.83 \\
\hline Paris (PS) & 425 & 1 & 3 & 5 & 3.33 & 25 & 17.81 & 1.08 \\
\hline Antwerp City (AC) & 238 & 1 & 3 & 5 & 3.36 & 24 & 24.08 & 1.46 \\
\hline Barcelona (BA) & 272 & 1 & 3 & 6 & 3.56 & 25 & 22.21 & 1.39 \\
\hline Huelva (HU) & 204 & 2 & 5 & 7 & 4.38 & 40 & 17.29 & 1.56 \\
\hline Total & 7867 & 0 & 1 & 4 & 2.21 & 14 & 19.12 & 1.17 \\
\hline
\end{tabular}

Dash denotes not measured. 
Table 2 Ratios of mean annoyance scores from univariate negative binomial regression and $P$ values from tests of heterogeneity

\begin{tabular}{|c|c|c|}
\hline & $\begin{array}{r}\text { Ratio of mean } \\
\text { scores }(95 \% \text { CI })\end{array}$ & $\begin{array}{r}P \text { from } \\
\text { tests for } \\
\text { heterogeneity }\end{array}$ \\
\hline \multicolumn{3}{|l|}{ Gender } \\
\hline Men (reference) & 1 & \\
\hline Women & $1.22(1.15-1.28)$ & 0.083 \\
\hline \multicolumn{3}{|l|}{ Age (years) } \\
\hline$<35$ (reference) & 1 & \\
\hline $35-39$ & $0.91(0.82-1.00)$ & 0.821 \\
\hline $40-44$ & $0.98(0.89-1.08)$ & 0.988 \\
\hline $45-49$ & $1.01(0.92-1.11)$ & 0.964 \\
\hline$>50$ & $1.00(0.90-1.10)$ & 0.761 \\
\hline \multicolumn{3}{|c|}{ Education (age at end of education in years) } \\
\hline$<18$ (reference) & 1 & \\
\hline $19-22$ & $1.00(0.94-1.07)$ & 0.764 \\
\hline$>23$ & $0.98(0.91-1.04)$ & 0.058 \\
\hline \multicolumn{3}{|l|}{ Socio economic class } \\
\hline Manual occupation (reference) & 1 & \\
\hline Non-manual occupation & $1.07(1.00-1.15)$ & 0.066 \\
\hline Others (e.g. housewives) & $1.24(1.11-1.39)$ & 0.853 \\
\hline \multicolumn{3}{|l|}{ Respiratory symptoms } \\
\hline No symptoms (reference) & 1 & \\
\hline Wheezing & $1.22(1.14-1.32)$ & 0.789 \\
\hline Wheezing and breathless & $1.28(1.16-1.41)$ & 0.918 \\
\hline Dyspnea & $1.46(1.29-1.65)$ & 0.355 \\
\hline Night dyspnea & $1.25(1.10-1.41)$ & 0.760 \\
\hline Cough & $1.28(1.17-1.40)$ & 0.858 \\
\hline Phlegm & $1.36(1.23-1.50)$ & 0.315 \\
\hline Phlegm $>3$ months & $1.28(1.14-1.45)$ & 0.946 \\
\hline Ever asthma & $1.16(1.06-1.28)$ & 0.572 \\
\hline Current asthma & $1.24(1.07-1.44)$ & 0.820 \\
\hline Ever rhinitis & $1.14(1.07-1.21)$ & 0.309 \\
\hline Current rhinitis & $1.11(1.04-1.18)$ & 0.695 \\
\hline \multicolumn{3}{|l|}{ Exercise (days with exercise per week) } \\
\hline$\leqslant 3$ (reference) & 1 & \\
\hline $4-5$ & $0.99(0.91-1.08)$ & 0.938 \\
\hline $6-7$ & $0.98(0.91-1.06)$ & 0.970 \\
\hline \multicolumn{3}{|l|}{ Smoking } \\
\hline Never (reference) & 1 & \\
\hline Ex smoker & $1.02(0.94-1.09)$ & 0.912 \\
\hline Current smoker & $1.01(0.94-1.08)$ & 0.616 \\
\hline Passive smoking & $1.10(1.03-1.17)$ & 0.893 \\
\hline \multicolumn{3}{|l|}{ Exposure to traffic } \\
\hline No or infrequent traffic (reference) & 1 & \\
\hline Frequent or constant car traffic & $2.23(2.10-2.36)$ & $<0.001$ \\
\hline Frequent or constant truck traffic & $1.99(1.89-2.10)$ & $<0.001$ \\
\hline \multicolumn{3}{|l|}{ Season of the interview } \\
\hline Spring (reference) & 1 & \\
\hline
\end{tabular}

Table 2 Continued

\begin{tabular}{lrr}
\hline & $\begin{array}{r}\text { Ratio of mean } \\
\text { scores (95\% CI) }\end{array}$ & $\begin{array}{r}\boldsymbol{P} \text { from } \\
\text { tests for }\end{array}$ \\
heterogeneity
\end{tabular}

CI: confidence interval. Centre was entered as a fixed effect when $P$ for heterogeneity was $\geqslant 0.10$ and as a random effect, when $P$ for heterogeneity was $<0.10$.

except for gender ( $P$ value for heterogeneity $=0.083)$, high education $(P=0.058)$, non-manual workers $(P=0.066)$ and self-reported car and heavy vehicle traffic $(P<0.001)$. Heterogeneity for gender did not follow any specific pattern; women in Umeå (Sweden), Norwich (UK), Pavia (Italy), Oviedo (Spain), Montpellier (France), Basel (Switzerland) and Antwerp City (Belgium) reported significantly higher annoyance than men. In Ipswich (UK), Albacete (Spain) and Turin (Italy) they tended to report lower annoyance than men (Figure 2). Heterogeneity for high education and non-manual workers did not follow any specific patterns either. The association between annoyance and high education was statistically significant and positive only in Göteborg (Sweden). The association between annoyance and nonmanual workers was positive and statistically significant in Uppsala (Sweden) and Verona (Italy) and negative in Basel. For all other centres, the associations were not statistically significant and the confidence intervals included the pooled estimate.

The participants who reported high exposure to car traffic also tended to report higher annoyance: this association was statistically significant for all centres. Subjects from Northern centres tended to report higher annoyance when reporting high levels of car traffic than participants in Southern centres (Figure 3). Similarly, respondents who reported high levels of heavy vehicle traffic also tended to report greater annoyance. This association was statistically significant for all centres, except for Oviedo, Albacete and Huelva. The associations also tended to be stronger in Northern compared with Southern centres. In the multivariate analysis (Table 3), nocturnal shortness of breath, phlegm and rhinitis were the respiratory indicators significantly associated with annoyance, in addition to female gender, heavy traffic, high education, never smoking and exposure to ETS.

Figure 4 shows the association between the mean annoyance and $\mathrm{PM}_{2.5}$ and $\mathrm{S}$. The first panel illustrates the crude association; the second panel includes mean annoyance adjusted for all individual-level variables shown in Table 3, except traffic and the third panel includes the mean annoyance adjusted for all variables including traffic. The association was similar in the three panels for the two pollutants. The scatter plots for $\mathrm{PM}_{2.5}$ included three outliers from the Italian survey. After excluding the Italian data, results were as follows: slope 0.14 (SE 0.03 ) and $R^{2} 0.54$ for the crude model; slope 0.14 (SE 0.03 ) and $R^{2} 0.54$ for the adjusted model excluding traffic and slope 0.14 (SE 0.03) and $R^{2} 0.54$ for the adjusted model including the traffic variables. The models including the Italian 


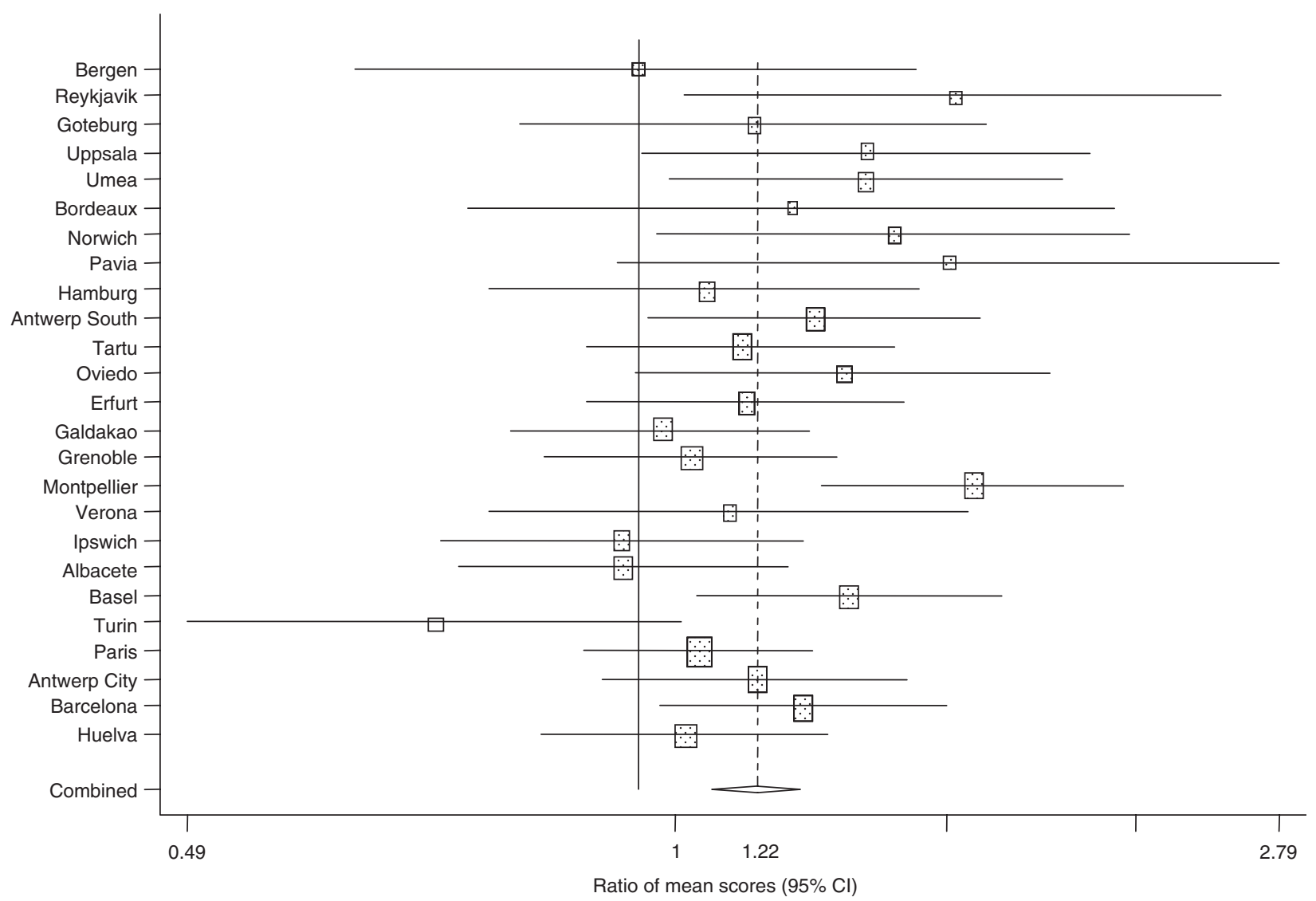

Figure 2 Crude ratios of mean annoyance scores comparing women with men by centre.

surveys gave a slope of $0.06(0.02)$ and $R^{2} 0.25$ (Figure $4 \mathrm{a}-\mathrm{c}$ ). The fully adjusted model for $S$ (Figure 4c) gave a slope of 1.43 and a $R^{2}$ of 0.37 , indicating that annoyance levels increased by 1.43 point per $1 \mu \mathrm{g} \mathrm{m}^{-3}$ increase in $\mathrm{S}$.

\section{Discussion}

\section{Principal findings}

This study highlights the importance of annoyance due to air pollution as $14 \%$ of the Europeans are highly annoyed by air pollution and more than half reported some degree of annoyance. Individual characteristics affect the reporting of annoyance, such as gender, socio-economic status, respiratory symptoms, exposure to ETS and self-reported traffic.

\section{Strengths and weaknesses of the study}

Due to the international setting of this study, our data cover a variety of scenarios and include a large number of observations. Annoyance is in itself an interesting measure of well-being and our unique cross-European study indicates complex and heterogeneous associations between the perception of environmental quality and background measures of pollution.

The lack of home outdoor air quality measurements is a major limitation of our study. While self-reported traffic density may be considered a marker for this missing information, the limitation of this questionnaire-based information needs to be emphasized, as perception of traffic may determine the reporting of annoyance. Our air pollution measures reflected 'urban background' levels. The participants from the same centre were assigned the same level of pollution, however, only some of them live close to very busy streets. Thus, self-reported traffic intensity may serve as a proxy for additional air pollution (or annoyance) beyond what is due to background air pollution. In the analysis, using the individually adjusted mean of annoyance by centre, the association between air pollution and annoyance was very similar including or excluding traffic from the multivariate regression model.

In Texas, Brody et al. ${ }^{19}$ showed that the public perception of air quality was not correlated with actual measures of air quality, but it was very strongly influenced by individual factors such as setting, state identification and socio-economic characteristics.

$\mathrm{PM}_{2.5}$ is more affected by the location of the monitor while $S$ is less related to the distance between the monitor and source of the pollutant. ${ }^{20}$ In this study, the monitors from the three Italian centres were in busy streets, reflecting a traffic situation instead of the urban background. Thus, the most appropriate marker of urban background pollution, measured at a single monitor, is the S content. However, spatial heterogeneity of $\mathrm{PM}_{2.5}$ is rather limited as well. Thus, as shown, whether we use 


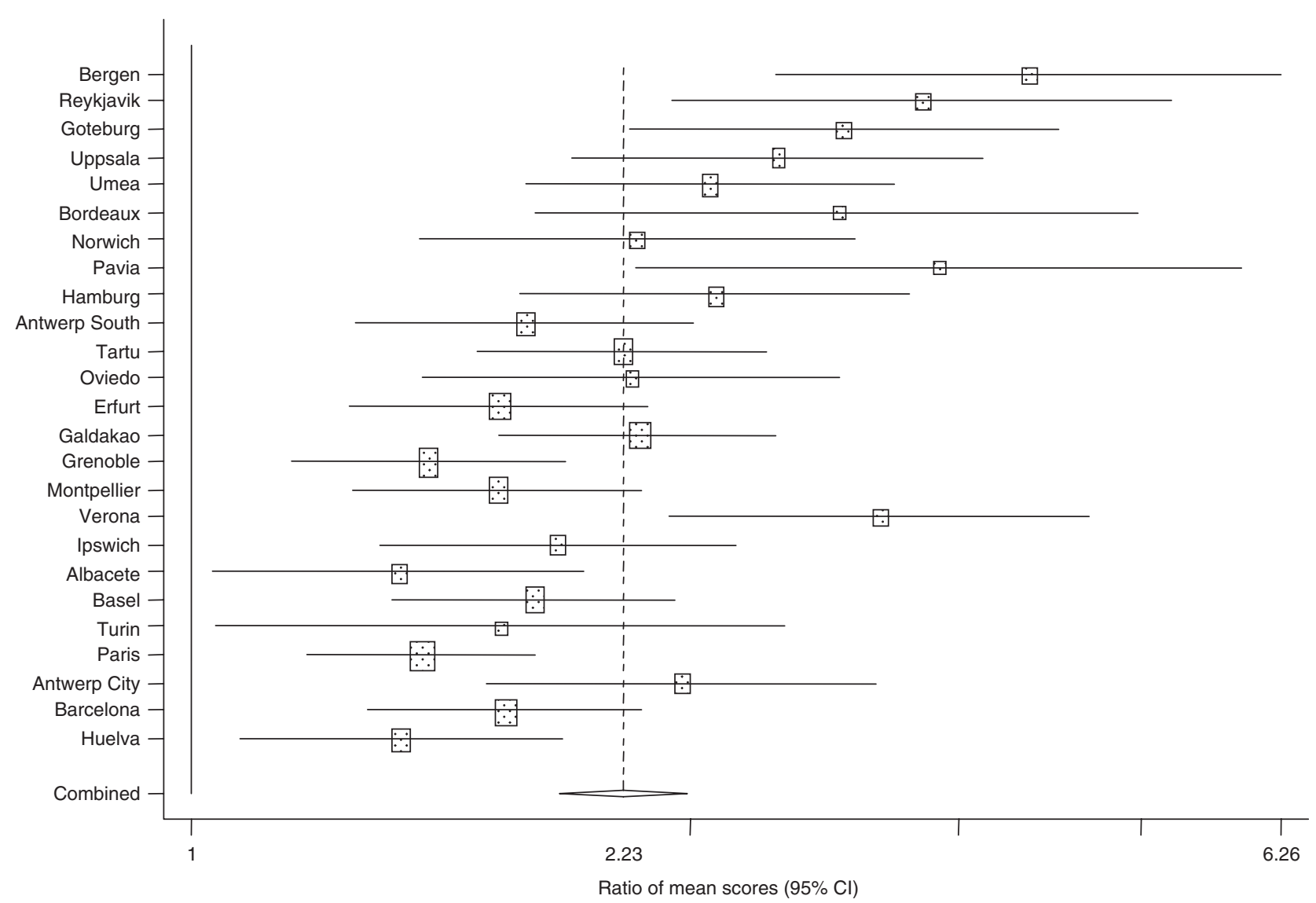

Figure 3 Crude ratios of mean annoyance scores comparing frequent or constant exposure to car traffic with no or infrequent exposure by centre.

$\mathrm{S}$ or $\mathrm{PM}_{2.5}$ as markers of background pollution has little influence on the results.

\section{Comparison with other studies}

The general distribution of annoyance was different from those described in other studies, as the percentage of subjects reporting very high annoyance $(>8$ on the scale in the Swiss SAPALDIA study ${ }^{9}$ or $>7$ in the EXPOLIS study, including Finland, Greece and Czech Republic ${ }^{10}$ ) is lower in this study. Also, the percentage of subjects reporting no annoyance is higher. Annoyance varies widely across Europe, showing a gradient from North to South. In previous studies, Rotko et al. ${ }^{10}$ described that $6 \%$ of respondents were highly annoyed by air pollution at home in Helsinki, 7\% in Athens, 3\% in Basel, $4 \%$ in Milan, $6 \%$ in Oxford and 25\% in Prague, in comparison with $18 \%$ in eight Swiss cities ${ }^{9}$ and $5-17 \%$ in 55 selected Swedish urban areas. ${ }^{8}$ The variables associated with annoyance in this study are quite consistent with the ones described previously, mainly for gender, socio-economic status and subjects with respiratory symptoms. Forsberg et al. ${ }^{8}$ and Williams et al. ${ }^{8,11}$ described that women, middle-aged people and subjects suffering from respiratory symptoms reported higher scores at the same pollution level. Rotko et al. found that women, non-white-collar workers and those living downtown in Helsinki perceived annoyance more often at home but they found little differences for other variables, such as age, respiratory symptoms, smoking status or ETS exposure. $^{12}$ In a study of six European cities, Rotko et al. found an association between air pollution annoyance and female gender, respiratory symptoms, sensitiveness to air pollution and living downtown, but not with age, education, smoking status or having children. ${ }^{10}$ Our comparison of the city average annoyance and centre pollution level does not confirm previous multi-centre findings such as those from Switzerland. ${ }^{9}$ The substantial cultural and environmental heterogeneity across ECRHS centres as compared with the more homogenous Swiss population sample may partly explain this discrepancy.

\section{Interpretation of determinants of annoyance}

Several studies observed higher annoyance scores among women $^{6,8,10,12}$ and some have argued that women are in general more sensitive to environmental risks. ${ }^{21}$ It has been proposed that women have more environmental conscience, and some authors have suggested that women in general have a better sense of smell than males. ${ }^{22,23}$ However, it is still unclear why women could be more affected by air pollution ${ }^{8,24}$ and our data reveal differences across cities with men reporting higher annoyance in some centres. We hypothesize that in some cities women may spend more time at home, ${ }^{25-27}$ thus having a better perception of the home environment. Adult women in the EXPOLIS study spent more time at home 
Table 3 Ratios of mean annoyance scores from multivariate negative binomial regression

\begin{tabular}{|c|c|}
\hline & $\begin{array}{r}\text { Ratio of mean scores } \\
(95 \% \mathrm{CI})\end{array}$ \\
\hline \multicolumn{2}{|l|}{ Gender } \\
\hline Men (reference) & 1 \\
\hline Women & $1.17(1.10-1.24)$ \\
\hline \multicolumn{2}{|l|}{ Socioeconomic class } \\
\hline Manual occupation (reference) & 1 \\
\hline Non-manual occupation & $1.01(0.93-1.09)$ \\
\hline Others (e.g. housewives) & $1.07(0.94-1.22)$ \\
\hline \multicolumn{2}{|l|}{ Respiratory symptoms } \\
\hline None (reference) & 1 \\
\hline Night dyspnea & $1.33(1.17-1.50)$ \\
\hline Phlegm & $1.27(1.15-1.40)$ \\
\hline Ever rhinitis & $1.07(1.01-1.14)$ \\
\hline \multicolumn{2}{|l|}{ Smoking } \\
\hline Never (reference) & 1 \\
\hline Ex smoker & $1.02(0.95-1.09)$ \\
\hline Current smoker & $0.94(0.87-1.01)$ \\
\hline Passive smoking & $1.10(1.03-1.18)$ \\
\hline \multicolumn{2}{|l|}{ Exposure to traffic } \\
\hline No or infrequent traffic (reference) & 1 \\
\hline Frequent or constant car traffic & $1.69(1.58-1.82)$ \\
\hline Frequent or constant truck traffic & $1.48(1.38-1.59)$ \\
\hline
\end{tabular}

CI: confidence interval. Multivariate model adjusted for all variables listed and centre.

on average, from $2.5 \mathrm{~h}$ more in Athens to 10 min less in Prague. ${ }^{27}$ It will be necessary to use qualitative and quantitative methods to gain a better understanding of the difference between men's and women's risk perception. ${ }^{28}$

Although not surprising, the reason why subjects with respiratory indicators report higher scores of annoyance is unclear. It could be the fact that having respiratory symptoms makes them more sensitive and vulnerable to irritant substances such as air pollution. ${ }^{29}$ Another explanation could be that symptomatic subjects, in general, spend more time at home. Subjects with respiratory symptoms could also be more likely to associate air pollution with a risk of respiratory disease, or be more aware of the risks of air pollution and therefore overstate their actual personal level of annoyance. ${ }^{30}$ However, it is of interest that none of the asthma-related symptoms was associated with annoyance in the multivariate analysis. In the bivariate analysis, only 'ever asthma' and 'have presented an asthma attack in the last 12 months' were associated with annoyance but the associations were not very strong perhaps due to the improvement of asthma treatment relative to previous studies, which showed that asthmatic subjects are more sensitive to air pollution. ${ }^{31}$

Socio-economic status was only associated with annoyance in the crude analysis. Non-manual workers tended to report more annoyance but this association was only marginally significant. The non-classified subjects tended to report higher annoyance than the manual workers. This group consisted mainly of housewives and students, as they tend to spend more time at home during the day, when there is more traffic, it is expected that they become more annoyed by air pollution.

The fact that smokers are less likely to report high levels of annoyance can be explained by the fact that smokers tend to have a lower perceived risk of health-related problems and are also less concerned about their health. ${ }^{32}$ Another explanation could be that they are used to high smoke exposures and are less aware of ambient air quality.

As opposed to smokers, those exposed to ETS tended to report greater annoyance, which could be due to the fact that they are more sensitive to air quality. ${ }^{33}$

In general, annoyance was associated with reported traffic density at home, both for cars and heavy vehicles, but associations were heterogeneous. Southern centres tended to report higher levels of annoyance when reporting high traffic frequencies. Despite the fact that these individuals generally experience less traffic, they may be more sensitive to traffic, or they may be closer to streets or live in street canyons in some of the densely populated Southern cities of ECRHS. Although regional pollution was in general associated with average annoyance, we observed substantial scatter across these cities and countries. Annoyance at home most likely reflects local (traffic) pollution rather than the regional air quality. To test this hypothesis, we also adjusted for the reported traffic density at home, which may capture both local traffic density and the perception thereof. However, results changed only marginally with substantial cross-city variation. As a general pattern, people living in polluted cities reported, on average, a higher annoyance due to air pollution, but it is necessary to interpret that correlation cautiously as mean annoyance varied across communities with very similar ambient air quality.

\section{Implications for policymakers}

On the basis of our results, we caution against the use of community mean annoyance as a surrogate for regional air pollution. Although this may be appropriate across communities of similar cultural and environmental conditions, 'annoyance' appears to be much more complex in a crosscultural international context since annoyance is a subjective measure. It represents the subjectivity of the participant and incorporates dimensions such as dread, fear in the face of the unknown or anxiety. Annoyance due to noise has been related to physical and psychological conditions. ${ }^{7,34-36}$ Similar studies have not been done for air pollution annoyance. Aggregate Public Health indicators which include air pollution and residential noise have been proposed to assess the health of a population. ${ }^{37}$ Also, some authors have shown that people are concerned with air pollution ${ }^{29,38,39}$ and have proposed that to fully evaluate the impact of air pollution on health, it is necessary to not only assess the chemical aspect but also the circumstances, including the social ones, of the subject. ${ }^{29}$ Many factors have to be taken into account when assessing the relationship between air pollution levels such as air pollution perception and beliefs on air pollution risks. ${ }^{29}$ Air pollution might trigger annoyance by physical or psychological mechanisms. The former would include acute symptoms directly caused by air pollution. It has been recognized that air pollution 
(a)
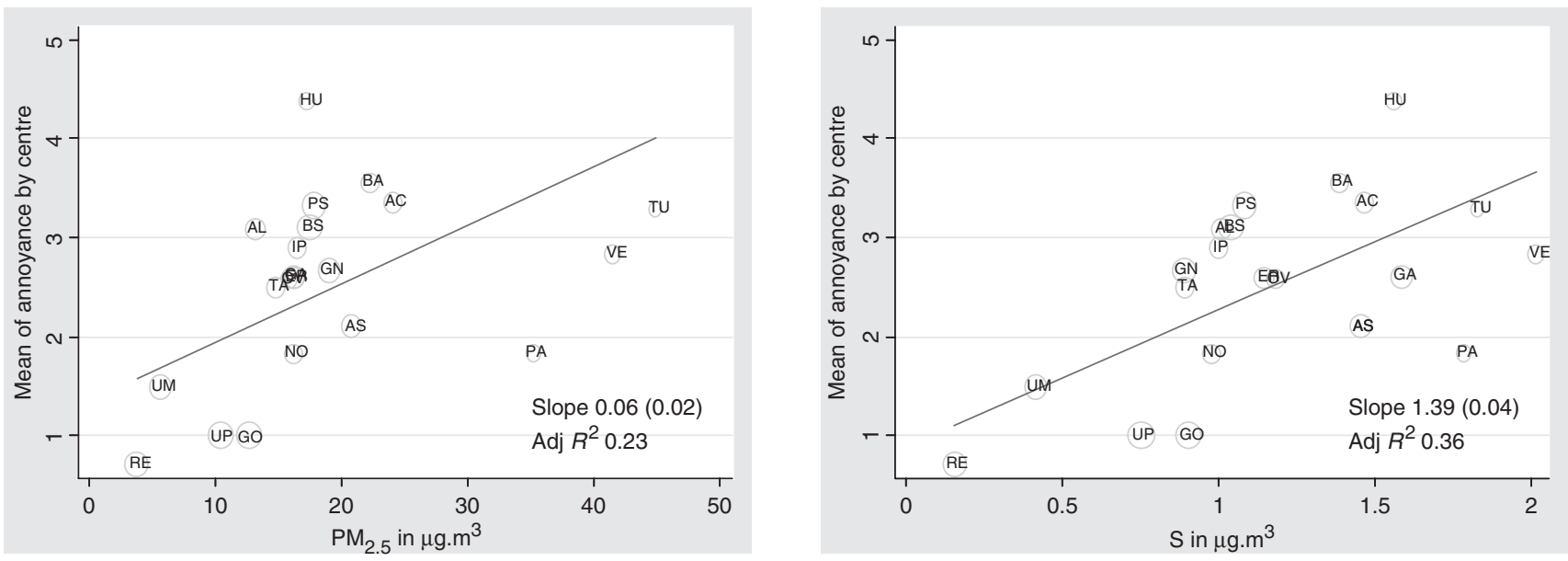

(b)
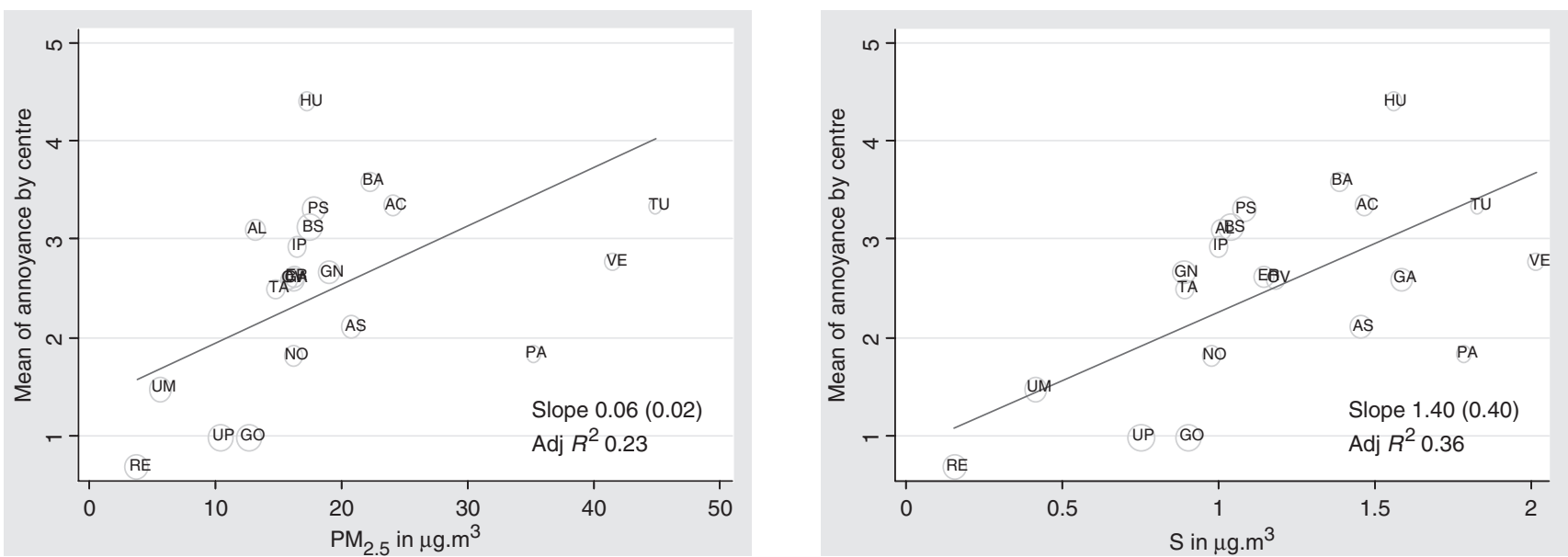

(c)
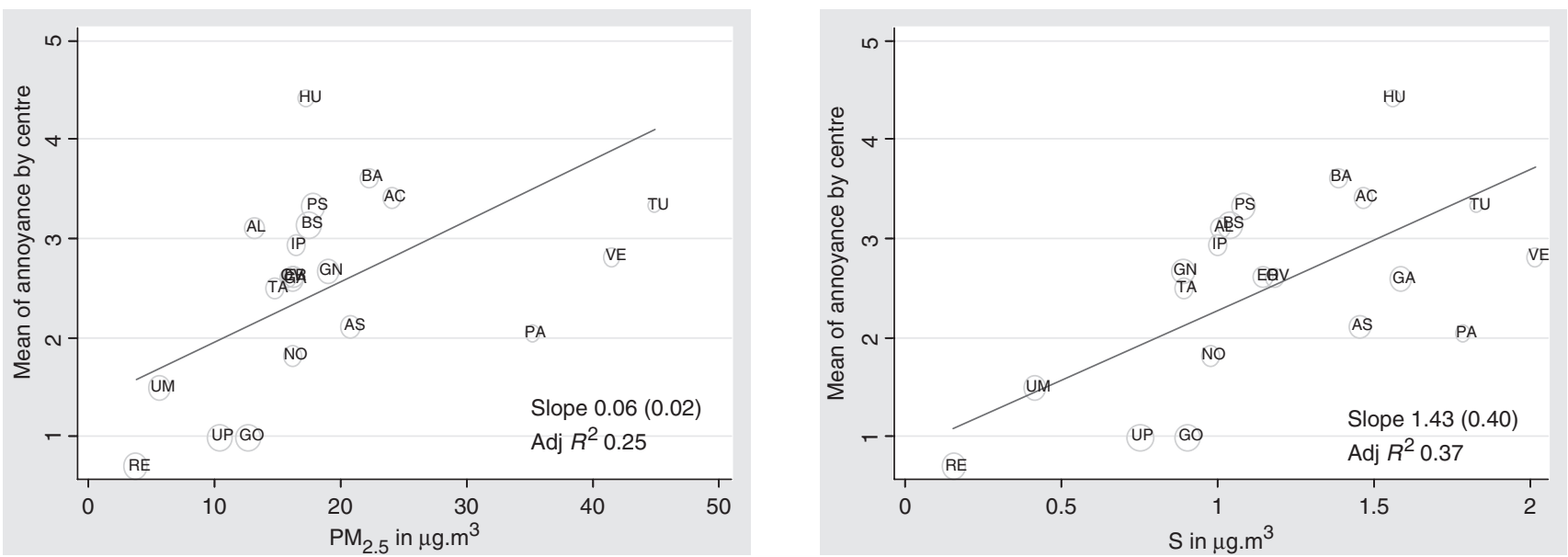

Figure 4 Plots of mean annoyance scores against $\mathrm{PM}_{2.5}$ and $\mathrm{S}$ levels at each centre and estimated change in mean of annoyance per $1 \mu \mathrm{g} \mathrm{m}^{-3}$ increase in $\mathrm{PM}_{2.5}$ and $\mathrm{S}$. The slope (standard error) and $R^{2}$ (adjusted for degrees of freedom) are shown. The size of circles indicates the weight of each centre in the regression analysis. (a) Mean annoyance versus $\mathrm{PM}_{2.5}$ and $\mathrm{S}$, crude. (b) Mean annoyance versus $\mathrm{PM}_{2.5}$ and $\mathrm{S}$, individually adjusted for all the variables of Table 3 except traffic. (c) Mean annoyance versus $\mathrm{PM}_{2.5}$ and $\mathrm{S}$, individually adjusted for all the variables of Table 3 including traffic. 
is associated with headache, rhinitis, cough, eye irritation. ${ }^{40-42}$ Subjects might attribute these to air pollution and therefore report annoyance. On the other hand, people may be aware of the risks of air pollution ${ }^{38,39}$ from which they cannot usually escape. This may cause frustration and lead to higher annoyance.

The individual's perception of air pollution is also a key issue in the development of new policies of risk assessment and management. Risk perception is a complex matter that includes social, political and cultural aspects ${ }^{38}$ and annoyance due to air pollution is only one of the aspects related to air pollution risk perception. Thus, we conclude that individuals' annoyance due to air pollution, although not valid as a measure of true air quality, may be a useful measure of perceived ambient quality. It can easily be monitored in surveys, across Europe, and may put environmental policies into perspective of people's perception and help locate populations with the biggest needs for environmental changes.

\section{Unanswered questions and future research}

Despite the large size of this study and its international setting, we did not find a strong association between annoyance and air pollution measurements. Objective characterization of environmental exposures would be necessary to fully disentangle individual, social, cultural and environmental determinants of annoyance or perceived air quality at home. Given the complex link between health, well-being, social factors, the environment and personal choices, prospective studies, including personal or home-based air pollution measurements, may be of particular value.

\section{Acknowledgements}

The co-ordination of ECRHS II was supported by the European Commission, as part of their Quality of Life programme. The following bodies funded the local studies in ECRHS II included in this article: Albacete: Fondo de Investigaciones Sanitarias (FIS) (grant code: 97/0035-01, 99/0034-01 and 99/0034-02), Hospital Universitario de Albacete, Consejería de Sanidad; Antwerp: FWO (Fund for Scientific Research)-Flanders Belgium (grant code: G.0402.00), University of Antwerp, Flemish Health Ministry; Barcelona: SEPAR, Public Health
Service (grant code: R01 HL62633-01), Fondo de Investigaciones Santarias (FIS) (grant code: 97/0035-01, 99/0034-01 and 99/0034-02) CIRIT (grant code: 1999SGR 00241) 'Instituto de Salud Carlos III' Red de Centros RCESP, C03/09 and Red RESPIRA, C03/011; Basel: Swiss National Science Foundation, Swiss Federal Office for Education \& Science, Swiss National Accident Insurance Fund (SUVA); Bergen: Norwegian Research Council, Norwegian Asthma \& Allergy Association (NAAF), Glaxo Wellcome AS, Norway Research Fund; Bordeaux: Institut Pneumologique d'Aquitaine; Erfurt: GSF-National Research Centre for Environment \& Health, Deutsche Forschungsgemeinschaft (DFG) (grant code FR 1526/1-1); Galdakao: Basque Health Dept; Göteborg: Swedish Heart Lung Foundation, Swedish Foundation for Health Care Sciences \& Allergy Research, Swedish Asthma \& Allergy Foundation, Swedish Cancer \& Allergy Foundation; Grenoble: Programme Hospitalier de Recherche Clinique-DRC de Grenoble 2000 no. 2610, Ministry of Health, Direction de la Recherche Clinique, Ministère de l'Emploi et de la Solidarité, Direction Générale de la Santé, CHU de Grenoble, Comite des Maladies Respiratoires de l'Isère; Hamburg: GSF-National Research Centre for Environment \& Health, Deutsche Forschungsgemeinschaft (DFG) (grant code MA 711/4-1); Ipswich and Norwich: National Asthma Campaign (UK); Huelva: Fondo de Investigaciones Sanitarias (FIS) (grant code: 97/0035-01, 99/0034-01 and 99/0034-02); Montpellier: Programme Hospitalier de Recherche Clinique-DRC de Grenoble 2000 no. 2610, Ministry of Health, Direction de la Recherche Clinique, CHU de Grenoble, Ministère de l'Emploi et de la Solidarité, Direction Générale de la Santé, Aventis (France), Direction Régionale des Affaires Sanitaires et Sociales Languedoc-Roussillon; Oviedo: Fondo de Investigaciones Santarias (FIS) (grant code: 97/0035-01, 99/0034-01 and 99/ 0034-02); Paris: Ministère de l'Emploi et de la Solidarité, Direction Générale de la Santé, UCB-Pharma (France), Aventis (France), Glaxo France, Programme Hospitalier de Recherche Clinique-DRC de Grenoble 2000 no. 2610, Ministry of Health, Direction de la Recherche Clinique, CHU de Grenoble; Pavia: Glaxo-SmithKline Italy, Italian Ministry of University and Scientific and Technological Research (MURST), Local University Funding for research 1998 \& 1999 (Pavia, Italy); Reykjavik: Icelandic Research Council, Icelandic University Hospital Fund; Tartu: Estonian Science

\section{KEY MESSAGES}

- Annoyance due to air pollution reflects the perception of the air quality.

- This study investigates personal, socio-demographic and environmental determinants of annoyance due to air pollution in a large international multicultural European study.

- Women, never smokers, the well educated and subjects with respiratory health problems reported higher annoyance.

- Self reported traffic and passive smoking correlated with annoyance, and subjects in the Northern European countries reported less annoyance.

- Central means of urban background pollution $\left(\mathrm{PM}_{2.5}\right.$ and S) were moderately correlated with adjusted central means of annoyance but the report of annoyance within city varied substantially. 
Foundation; Turin: ASL 4 Regione Piemonte (Italy), AO CTO/ ICORMA Regione Piemonte (Italy), Ministero dell'Università e della Ricerca Scientifica (Italy), Glaxo Wellcome spa (Verona, Italy); Umea: Swedish Heart Lung Foundation, Swedish Foundation for Health Care Sciences \& Allergy Research, Swedish Asthma \& Allergy Foundation, Swedish Cancer \& Allergy Foundation; Uppsala: Swedish Heart Lung Foundation, Swedish Foundation for Health Care Sciences \& Allergy Research, Swedish Asthma \& Allergy Foundation, Swedish Cancer \& Allergy Foundation; Verona: University of Verona; Italian Ministry of University and Scientific and Technological Research (MURST); Glaxo-SmithKline Italy.

Conflict of interest: None declared.

\section{References}

${ }^{1}$ Brook RD, Franklin B, Cascio W et al. Air pollution and cardiovascular disease: a statement for healthcare professionals from the Expert Panel on Population and Prevention Science of the American Heart Association. Circulation 2004;109:2655-71.

${ }^{2}$ Brunekreef B, Holgate ST. Air pollution and health. Lancet 2002;360:1233-42.

${ }^{3}$ Kunzli N, Kaiser R, Medina $S$ et al. Public-health impact of outdoor and traffic-related air pollution: a European assessment. Lancet 2000;356:795-801.

${ }^{4}$ Nuckols JR, Ward MH, Jarup L. Using geographic information systems for exposure assessment in environmental epidemiology studies. Environ Health Perspect 2004;112:1007-15.

${ }^{5}$ Klepeis NE, Nelson WC, Ott WR et al. The National Human Activity Pattern Survey (NHAPS): a resource for assessing exposure to environmental pollutants. $J$ Expo Anal Environ Epidemiol 2001;11:231-52.

${ }^{6}$ Williams ID, Bird A. Public perceptions of air quality and quality of life in urban and suburban areas of London. J Environ Monit 2003;5:253-59.

${ }^{7}$ Passchier-Vermeer W, Passchier WF. Noise exposure and public health. Environ Health Perspect 2000; 108:123-31.

${ }^{8}$ Forsberg B, Stjernberg N, Wall S. People can detect poor air quality well below guideline concentrations: a prevalence study of annoyance reactions and air pollution from traffic. Occup Environ Med 1997;54:44-48.

${ }^{9}$ Oglesby L, Kunzli N, Monn C, Schindler C, Ackermann-Liebrich U, Leuenberger P. Validity of annoyance scores for estimation of long term air pollution exposure in epidemiologic studies: the Swiss Study on Air Pollution and Lung Diseases in Adults (SAPALDIA). Am J Epidemiol 2000;152:75-83.

${ }^{10}$ Rotko T, Oglesby L, Kunzli N, Carrer P, Nieuwenhuijsen MJ, Jantunen M. Determinants of perceived air pollution annoyance and association between annoyance scores and air pollution (PM2.5, NO2) concentrations in the European EXPOLIS study. Atmos Env 2002;36:4593-602.

${ }^{11}$ Williams ID, McCrae IS. Road traffic nuisance in residential and commercial areas. Sci Total Environ 1995;169:75-82.

12 Rotko T. Social Aspects of Air Pollution: Sociodemographic Differences in Exposure, Perceived Annoyance and Concern about Air Pollution Laboratory of Air Hygiene, Department of Environmental Health, National Public Health Institute, Kuopio, Finland, 2004.

${ }^{13}$ Burney PG, Luczynska C, Chinn S, Jarvis D. The European Community Respiratory Health Survey. Eur Respir J 1994;7:954-60.
${ }^{14}$ The European Community Respiratory Health Survey II. Eur Respir J 2002;20:1071-79.

${ }^{15}$ Götschi T, Hazenkamp-von Arx ME et al. Elemental Composition and Light Absorbance of Ambient Fine Particles at 21 European Locations. Submitted to Amos Env 2004.

${ }^{16}$ Hazenkamp-von Arx ME, Gotschi FT, Oglesby L. et al. PM2.5 and NO2 assessment in 21 European study centres of ECRHS II: annual means and seasonal differences. Atmos Env 2004;53:617-28.

${ }^{17}$ Hazenkamp-von Arx ME, Gotschi FT, Oglesby L et al. PM2.5 assessment in 21 European study centers of ECRHS II: Method and first winter results. J Air Waste Manag Assoc 2003;53:617-28.

${ }^{18}$ DerSimonian R, Laird N. Meta-analysis in clinical trials. Control Clin Trials 1986;7:177-88.

${ }^{19}$ Brody SD, Peck BM, Highfield WE. Examining localized patterns of air quality perception in Texas: A spatial and statistical analysis. Risk Anal 2004;24:1561-74.

${ }^{20}$ Kim E, Hopke PK, Pinto JP, Wilson WE. Spatial variability of fine particle mass, components, and source contributions during the regional air pollution study in St. Louis. Environ Sci Technol 2005;39:4172-79.

${ }^{21}$ Flynn J, Slovic P, Mertz CK. Gender, Race, and Perception of Environmental-Health Risks. Risk Anal 1994;14:1101-08.

22 Bengtsson S, Berglund H, Gulyas B, Cohen E, Savic I. Brain activation during odor perception in males and females. Neuroreport 2001;12:2027-33.

${ }^{23}$ Ship JA, Weiffenbach JM. Age, gender, medical treatment, and medication effects on smell identification. $J$ Gerontol 1993;48:M26-M32.

24 Johnson BB. Gender and race in beliefs about outdoor air pollution. Risk Anal 2002;22:725-38.

${ }^{25}$ Graham SE, McCurdy T. Developing meaningful cohorts for human exposure models. $J$ Expo Anal Environ Epidemiol 2004; 14:23-43.

${ }^{26}$ McCurdy T, Graham SE. Using human activity data in exposure models: analysis of discriminating factors. $J$ Expo Anal Environ Epidemiol 2003;13:294-317.

${ }^{27}$ Schweizer C, Edwards R, Bayer-Oglesby L et al. Indoor TimeMicroenvironment-Activity Patterns in seven Regions of Europe. $J$ Exp Science Env Epidemiol Advance online publication 17 May 2006; doi: $10.1038 /$ sj.jes.7500490.

${ }^{28}$ Gustafson PE. Gender differences in risk perception: theoretical and methodological perspectives. Risk Anal 1998;18:805-11.

${ }^{29}$ Hunter PR, Davies MA, Hill H, Whittaker M, Sufi F. The prevalence of self-reported symptoms of respiratory disease and community belief about the severity of pollution from various sources. Int $J$ Environ Health Res 2003;13:227-38.

${ }^{30}$ Hunter PR, Bickerstaff K, Davies MA. Potential sources of bias in the use of individual's recall of the frequency of exposure to air pollution for use in exposure assessment in epidemiological studies: a crosssectional survey. Environ Health 2004;3:3.

${ }^{31}$ Chipps BE. Determinants of asthma and its clinical course. Annals of Allergy Asthma o Immunology 2004;93:309-16.

32 Oncken C, Mckee S, Krishnan-Sarin S, O'Malley S, Mazure CM. Knowledge and perceived risk of smoking-related conditions: a survey of cigarette smokers. Prev Med 2005;40:779-84.

33 Junker MH, Danuser B, Monn C, Koller T. Acute sensory responses of nonsmokers at very low environmental tobacco smoke concentrations in controlled laboratory settings. Environ Health Perspect 2001;109:1045-52.

${ }^{34}$ Stansfeld S, Haines M, Brown B. Noise and health in the urban environment. Rev Environ Health 2000;15:43-82. 
${ }^{35}$ Stansfeld SA, Matheson MP. Noise pollution: non-auditory effects on health. Br Med Bull 2003;68:243-57.

${ }^{36}$ Staples SL. Human response to environmental noise. Psychological research and public policy. Am Psychol 1996;51:143-50.

${ }^{37}$ de Hollander AE, Melse JM, Lebret E, Kramers PG. An aggregate public health indicator to represent the impact of multiple environmental exposures. Epidemiology 1999;10:606-17.

${ }^{38}$ Bickerstaff K. Risk percepton research: socio-cultural perspectives on the public experience of air pollution. Environ Int 2004;30:827-40.
${ }^{39}$ Elliott SJ, Cole DC, Krueger P, Voorberg N, Wakefield S. The power of perception: health risk attributed to air pollution in an urban industrial neighbourhood. Risk Anal 1999;19:621-34.

${ }^{40}$ Chen B, Hong C, Kan H. Exposures and health outcomes from outdoor air pollutants in China. Toxicology 2004;198:291-300.

${ }^{41}$ Tarlo SM. Cough: occupational and environmental considerations: ACCP evidence-based clinical practice guidelines. Chest 2006;129(Suppl 1)186S-196S.

${ }^{42}$ Zuskin E, Mustajbegovic J, Schachter EN et al. Respiratory findings in mail carriers. Int Arch Occup Environ Health 2000;73:136-43.

\title{
Commentary: Linking particulate matter and sulphur concentrations to air pollution annoyance: problems of measurement, scale and control
}

\author{
Samuel D Brody ${ }^{1 *}$ and Sammy Zahran ${ }^{2}$
}

\author{
Accepted 2 April 2007
}

Jacquemin et al. address an important topic in the field of epidemiology and public health by increasing understanding of the triggers of air pollution annoyance across 25 population centres in 14 countries in Europe. No study, however commendable, is without its limitations and this one is no exception. We offer a commentary of their article 'Annoyance Due to Air Pollution in Europe' as a means to enhance future study of air pollution perceptions. Our assessment focuses on three elements of their research: (i) measurement of the dependent variable, air pollution annoyance; (ii) problems associated with the spatial scale used to estimate air pollution exposure and (iii) the exclusion of statistical controls routinely used in the risk perception literature.

\footnotetext{
${ }^{1}$ Environmental Planning \& Sustainability Research Unit, Hazard Reduction and Recovery Center, Department of Landscape Architecture and Urban Planning, Texas A\&M University, TAMU 3137, College Station, TX 778433137, USA.

2 Department of Sociology, Colorado State University, B235 Clark Building, Fort Collins, CO 80523-1784, USA.

* Corresponding author. Environmental Planning \& Substainability Research Unit, Hazard Reduction and Recovery Center, Department of Landscape Architecture and Urban Planning, Texas A\&M University, TAMU 3137, College Station, TX 77843-3137, USA. E-mail: sbrody@archmail.tamu.edu
}

\section{Measuring air pollution annoyance}

A potential problem with the measurement of the dependent variable is the restriction of the question of air pollution annoyance to the specific condition of keeping a window open. By this restriction, Jacquemin et al. are measuring how annoyed or disturbed a person is by outdoor air pollution when indoors. Not surprisingly, under this unusually specific condition, $43 \%$ of respondents score their level of outdoor air pollution annoyance at zero.

Jacquemin et al. also report that respondents from Northern European cities have substantially lower levels of air pollution annoyance. This variance in air pollution annoyance by city is partially explained by data on fine particulate matter $\left(\mathrm{PM}_{2.5}\right)$ and sulphur (S) concentrations. For example, Figure 4a in their manuscript illustrates the relationship between mean air pollution annoyance scores and $\mathrm{PM}_{2.5}$ and $\mathrm{S}$ levels for each city. For every unit increase $\left(\mu \mathrm{g} / \mathrm{m}^{3}\right)$ in $\mathrm{PM}_{2.5}$ and $\mathrm{S}$, we observe a modest increase in mean annoyance scores. Adjusted $R^{2}$ values in 'crude' models are 0.23 for $\mathrm{PM}_{2.5}$ and 0.36 for $\mathrm{S}$.

Testing relationships between objective measures of air pollution and subjective reports of annoyance is perfectly reasonable. However, the construction of the question to derive annoyance scores may contaminate this effort. Recall, respondents are asked to indicate their level of annoyance with outdoor air pollution when indoors. Observed responses in air 